\title{
Edutainment and practice in video-based learning: enriching educational videos with interactive activities and games
}

\section{Alexandros Kleftodimos* and Georgios Lappas}

\author{
Department of Communication and Digital Media, \\ University of Western Macedonia, Greece \\ Email: kleftodimos@kastoria.teiwm.gr \\ Email: lappas@kastoria.teiwm.gr \\ *Corresponding author
}

\section{Georgios Evangelidis}

\author{
Department of Applied Informatics, \\ University of Macedonia, \\ Thessaloniki, Greece \\ Email: gevan@uom.edu.gr
}

\begin{abstract}
Video-based learning has a long history but the transfer of educational videos to the web has given a powerful potential to this form of learning. Today, there is an abundance of independent educators, trainers, and educational organisations that use online video for educational content delivery. In most cases however, the videos that exist in educational platforms do not contain any aspects of interactivity and educational entertainment (edutainment). These are mostly non-interactive videos and in cases where there is interactivity this is mainly restricted to in-video quizzes and user annotations. The aim of this paper is to present solutions on how to develop interactive video-based learning environments using open source and freeware tools. In these solutions educational videos are enriched with knowledge testing activities, games, and hands-on practice exercises for learning software applications. The developed video-based learning environments were used and evaluated in classroom settings and some findings are reported in the paper.
\end{abstract}

Keywords: video-based learning; interactive videos; game-based learning; edutainment.

Reference to this paper should be made as follows: Kleftodimos, A., Lappas, G. and Evangelidis, G. (2020) 'Edutainment and practice in video-based learning: enriching educational videos with interactive activities and games', Int. J. Entertainment Technology and Management, Vol. 1, No. 1, pp.5-33.

Biographical notes: Alexandros Kleftodimos is a Lecturer of Multimedia Technologies at the Department of Communication and Digital Media, University of Western Macedonia, Greece. He holds a PhD in Computer Science from the Department of Applied Informatics, University of Macedonia, Greece. His research interests and published work are in the area of educational technologies, multimedia, web mining, social informatics, e-government and 
e-politics. He has participated in a number of national and EU funded research and development projects and in the past he also worked as a secondary education teacher in informatics and as a software developer and analyst.

Georgios Lappas is a Professor in Social and Political Informatics at the Communication and Digital Media Department, University of Western Macedonia, Greece. He served as the Chair of Department, Dean of Digital Media and Strategic Communication Lab, Dean and Vice-Dean of the MA 'Public Relations and Marketing with New Technologies' and Vice-Dean of the MSc 'Public Discourse and Digital Media'. He published more than 90 articles and served as PC member at more than 100 international conferences. He participated in many national and EU funded projects. His research interests include social informatics, e-marketing, web mining, opinion mining, e-government, and e-democracy.

Georgios Evangelidis is a Professor at the Department of Applied Informatics, School of Information Sciences, University of Macedonia, Thessaloniki, Greece. He is the Director of the Software and Data Engineering Laboratory of the Department and Dean of the School of Science and Technology of the International Hellenic University since 2016. His teaching, research interests and published work (about 120 papers and book chapters) are in the area of information management: databases, data mining, information retrieval, and geographic information systems. He has been coordinator and/or participant in more than 20 Greek Government and EU funded research and development projects.

\section{Introduction}

Video-based learning has been practiced for a long time and according to some researchers there are examples of video-based learning since the Second World War where soldiers were then trained with a combination of audio and film strips (Yousef et al., 2014b). Educational videos however, became known to a larger audience through television programs in the $60 \mathrm{~s}$. The educational videos at that time were produced exclusively by professionals and disseminated through the mainstream media at scheduled times. In the ' 70 s we have the appearance of the video cassette recorder known also as the VCR. The VCR was first used for recreational purposes but it was soon also introduced in classrooms and libraries for educational purposes. An article published by Reider (1985) highlighted the significant increase in the use of VCRs in schools in the mid-'80s.

Although video use for educational purposes witnessed an increase during that period it was later the evolution of the internet and the availability of video content on the web that contributed to a new and greater growth cycle of video-based learning. Today although educational videos are still broadcasted by mainstream channels, and libraries continue to hold significant video repositories either in analogue VHS format or in digital DVDs, educational videos are mainly distributed through the internet.

Today educational video distribution over the internet is a widespread practice. A vast amount of educational videos is offered in either an organised or unorganised manner, by institutions and independent educators in video-sharing sites such as YouTube (https://www.youtube.com) and Vimeo (http://www.vimeo.com). Additionally, massive 
online open courses (MOOCs) became an important part of education (Martin, 2012). Leading institutions deliver educational videos through MOOC initiatives, such as Coursera (https://www.coursera.org), edX (https://www.edx.org), and Stanford Online (https://online.stanford.edu). Furthermore, non-profit educational organisations, such as Khan Academy (https://www.khanacademy.org) as well as for-profit organisations such as Udacity (https://www.udacity.com) and Lynda.com (www.lynda.com), have organised large collections of educational videos for a broad range of subjects. There is also a vast number of educational videos created by independent trainers and educators that are freely available on YouTube or on paid platforms such as Udemy (www.udemy.com) and Learnworlds (https://www.learnworlds.com).

Educators typically use video as support material in K-12 and higher education and as a substitute for the physical lecture in distant education settings. Video also plays an important role in the application of the flipped classroom pedagogical model (Bishop and Verleger, 2013; Giannakos et al., 2014a) which reverses the traditional learning environment by delivering instructional content outside of the classroom with the use of web videos and other resources, and moving activities that have been traditionally considered as homework, into the classroom.

The forms of videos used in education can take many forms such as recorded lectures, Khan-style videos, documentaries, animations and so on, and although there is a broad range of video types today, videos in most cases lack interactive features and are mainly watched passively. This is evident from the literature reviews that have been written in the recent years and focus on video-based learning research (Kay, 2012; Giannakos, 2013; Giannakos et al., 2014b; Yousef et al., 2014a, 2014b). In 2012, Kay explored the video-based learning research by examining 53 peer-reviewed journal articles from 2002 to 2011. A year later Giannakos wrote a literature review by examining 166 articles published in educational technology journals from 2000 to 2012. Giannakos, Jaccheri, and Krogstie analyzed again these 166 articles in their 2014 paper which focuses on the MOOC rapid growth through the lens of video-based learning research. Yousef et al. (2014a) wrote another literature review after analysing 67 peer-reviewed papers published in educational technology journals from 2003 to 2013. The same year the authors continued their work by writing a broader literature review (Yousef et al., 2014b) based on the analysis of 127 peer-reviewed studies that have been conducted between 2003 and 2014. These studies were obtained after investigating the publications from 23 academic journals in the field of educational technology.

A striking observation is that in these literature reviews there is very little evidence of interactive video use. This observation was also made by Giannakos in his 2013 review of the video-based learning literature. In his paper, Giannakos concluded that there is a shift to more asynchronous and non-interactive systems which is surprising according to the author considering the evolution in web technologies. In Giannakos et al. (2014b) paper the authors again mention that there is an obvious trend to non-interactive systems. On most e-learning systems as well as on MOOCs there are many ways of interaction among the system and the learner but these interactions are detached from the video learning system and belong to the MOOC general learning context (e.g., assessment, tutor communication). The authors also mention that the video learning trend is in alignment with the design and the use of MOOCs.

The aim of this paper is to make a contribution to the research on interactive videos by providing a cost-efficient solution for enriching any video with interactive features using free and open source tools. More specifically, Section 2 presents a brief overview 
of interactive videos literature and the features that can be found in such videos. Section 3 provides technical details on how HTML5 players can be used to build interactive video-based environments for learning, and more specifically environments augmented with knowledge testing activities, games, and hands-on software practice exercises. Section 4 contains a thorough description of the interface and the functionalities of the developed environments. Section 5 presents how these environments were used and evaluated in educational settings. Finally, the paper concludes in Section 6.

\section{Interactive videos}

Interactive videos are not the norm in video-based learning settings and are not often encountered in the research related to educational videos as mentioned in the Introduction. However, there is a limited number of research efforts that deal with interactive videos and their effectiveness in learning. A number of papers are tracked by searching Scholar Google using appropriate search terms and then by looking at the reference section of these papers to track more papers. The interactive features that can be found in the related research are in most cases annotations and in-video quizzes. Video annotations or discussions are comments that learners add to the video at specific time points. By adding comments to the video content the learners can provide further clarifications, highlight points of interest, express reflections, raise issues and questions, and provide feedback. A number of video annotation (or video discussion) tools have been reported in literature through the years (Lin et al., 2003; Preston et al., 2005; Theodosiou et al., 2009; Rich and Hannafin, 2009; Motti et al., 2009; Colasante, 2011; Risko et al., 2013; Yousef et al., 2015; Agarwala et al., 2012).

In-video quizzes, on the other hand, are mainly multiple choice and open-ended questions that appear at appropriate times during video execution. One of the earliest papers to include embedded questions in videos was Schaffer and Hannafin (1986). Schaffer and Hannafin explored the effects of progressive interactivity by carrying out experiments with increasingly interactive versions of instruction. The interactive video that they used in one of their experiments made use of embedded questions and provided feedback to the learners regarding the accuracy of their answers. Despite the evidence that the authors provided on the effectiveness of interactive videos when compared to linear non-interactive versions, interactive videos were not really adopted in educational settings or research efforts in the years to follow. It was until recently and most likely due to the technological evolution of web video players that interactive videos enriched with in-video quizzes made their appearance again and have been the focus in a number of research studies (Cummins, et al., 2015; Wachtler et al., 2016; Kohen et al., 2016). Cummins et al. research results demonstrated that in-video quizzes were successful in creating an engaging and interactive mode of content delivery.

Besides in-video quizzes there also some other interactive features that are encountered in literature. Zhang et al. (2006) provided videos with random access to logical segments of the video by using appropriate 'prev' and 'next' buttons. These videos were also synchronised with lecture notes and powerpoint slides. Their findings suggest that students using interactive video achieved significantly better learning performance and a higher level of learner satisfaction than those in other settings (non-interactive video and classroom environment). Similarly, Merkt at al. (2011) explored random access in video (through the use of an index). They compared 
micro-level activities, such as stopping the video or browsing, to macro-level activities, such as referring to a table of contents or an index. Schwan and Riempp (2004) explored the effects of interactive videos and in their paper interactivity is confined to actions like stopping, replaying, reversing or changing speed to adapt the pace of the video demonstration.

Kolås (2015) presented four categories of interactive videos. Besides video with quizzes the author presented interactive video with links/link-chains, video with interactive 3D-objects and video with interactive maps. Girgensohn et al. (2003) presented Hyper-Hitchcock, a direct manipulation environment in which authors can combine video clips by placing hyperlinks between them. Hyper-Hitchcock can also automatically generate a hypervideo composed of multiple video summary levels and navigational links between these summaries and the original video.

The environments that are used in most of the research studies mentioned above are built by the research teams and the papers where these environments are presented do not provide in most cases any technical information on how these environments are developed. Today there are a number of commercial platforms for creating interactive videos and these platforms provide a different set of interactive options. Examples of such platforms are EDpuzzle (http://edpuzzle.com), Playposit (https://learn.playposit.com), Echo360 (https://echo360.com), HapYak (https://corp. hapyak.com/), EKO (https://studio.helloeko.com/), WireWax (https://www.wirewax. $\mathrm{com} /$ ) and Raptmedia (http://www.raptmedia.com/). These platforms provide user-friendly interfaces for adding interactive features to videos such as overlays, hotspots, in-video quizzes, annotations, chapter menus, custom animations, branching scenarios, etc. Vialogues (https://vialogues.com/) on the other hand is a free platform for creating video-based discussions. Educators can use Vialogues for free after creating an account.

Kleftodimos and Evangelidis (2016b), authors of this paper, presented a technical solution for creating interactive videos using the capabilities of open source HTML5 media players and their APIs. They also gave a series of examples of interactive features that can be incorporated into videos. These features include in-video quizzes, table of contents (with direct access to logical segments), and aggregation of web content and web applications with online videos. Examples of web applications which can be synchronised with educational video content include Google maps, SlideShare (online presentations), and Etherpad (collaborative writing application).

Today there is also an open source tool H5P (https://h5p.org/) which can be used for creating interactive content. In order to use the tool, someone has to add the H5P plugin into known content management and e-learning systems (i.e., Wordpress, Moodle, and Drupal). H5P was also developed using an HTML5 media player and it's API. Some of the interactions that can be found in $\mathrm{H} 5 \mathrm{P}$ are multiple choice questions, free text questions, mark the word activities, drag and drop text, pop-up text, etc. However, researchers, educators, and e-learning developers do not need to restrict themselves in any fixed set of features that the tools mentioned above provide. In the conference papers, Kleftodimos and Evangelidis (2016a, 2018), the work on interactive videos was continued by providing more ideas on how to rapidly develop new interactions by aggregating video content with existing web applications that are used in learning and knowledge testing. The current paper is an extension of this recent work and provides an integrated and detailed description of an economical way for augmenting videos with various knowledge testing activities, games, and hands-on software practice exercises 
using freeware and open source tools. Interactive video based learning environments built using the concepts explained in this paper were used and evaluated in educational settings and this paper also contains experiences gained from using these environments.

\section{Introducing interactivity with html5 players}

In order to develop interactive videos today, there are various available options and one of these options is the use of open source HTML5 players. Examples of HTML5 players are MediaElement.js (https://www.mediaelementjs.com/), Flowplayer (https://flowplayer .com) and Video.Js (https://videojs.com). The HTML5 players can play videos that are stored on web servers or act as a wrapper for videos hosted in video sharing websites such as YouTube, Vimeo, and DailyMotion. These players come with an application programming interface (API) that provide developers with a set of functions for controlling the video and handling events coming from the video. More specifically by using the video player API developers can create functions (or actions) that are triggered when specific time points (or intervals) are reached in the video timeline or when certain video events occur (e.g., pause, resume, start, and end of video, volume change). An action that can be triggered is the retrieval (or storage) of content from (or to) a database and this is the basis for building time-based interactive video applications. MediaElement.Js and its API functions were used for building the video-based learning environments described in this paper. The mechanism for retrieving and storing data from and to a database is depicted in Figure 1.

Figure 1 Retrieval (or storage) of content from (or to) a database (see online version for colours)

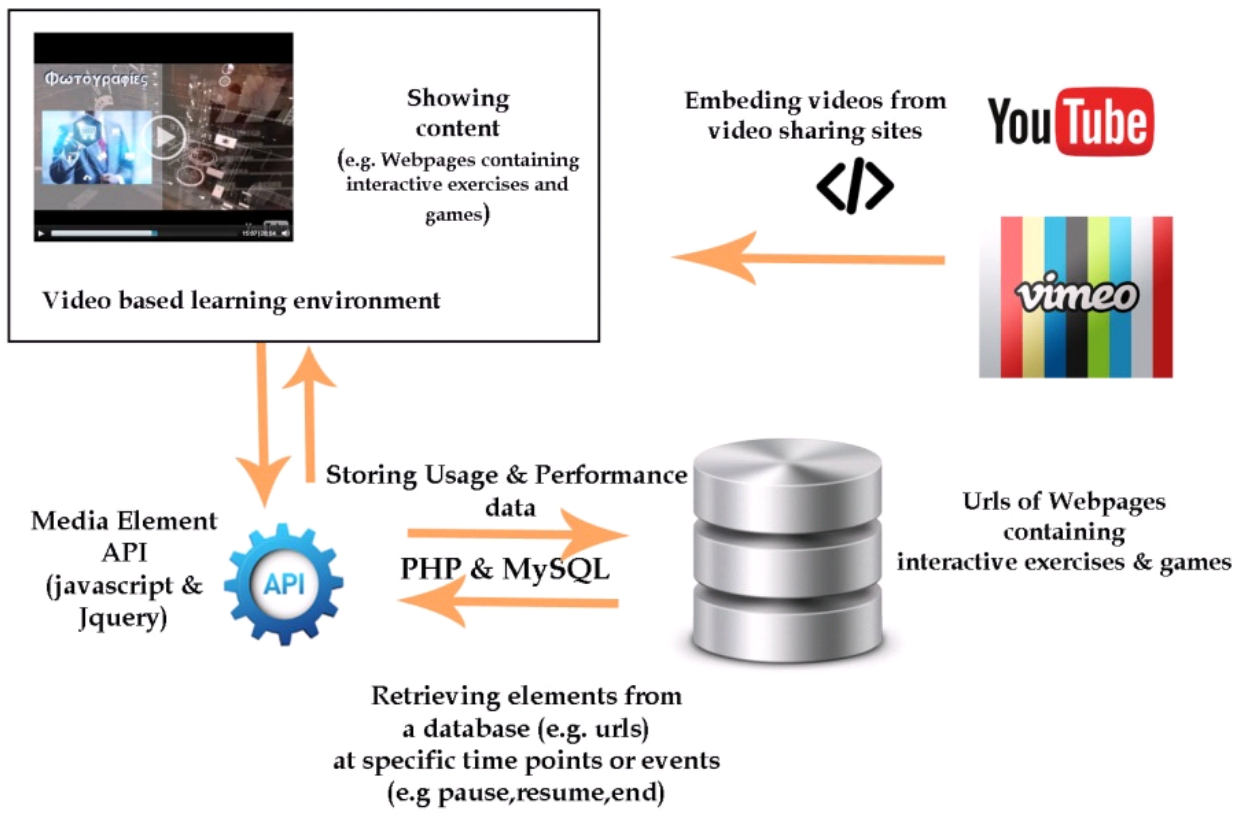


Using this technique various features could be incorporated into a video-based environment, like, in-video quizzes subtitles, sections, table of contents, video, and web content aggregation, discussions, etc. as described in Kleftodimos and Evangelidis (2016b). In the current paper, the data that will be retrieved from the database are links to webpages containing knowledge testing exercises and games as well as links that initiate online software programs that can be used in training sessions. Javascript (and Jquery) was used in the front end for dealing with the video API functions and PHP and MySQL were used in the back end.

According to various theories, there are better outcomes in terms of engagement and performance when interactivity is involved in learning. According to the ICAP framework (Chi and Wylie, 2014), there are four levels of cognitive engagement that are typically encountered in the learning process and these levels lead to different learning outcomes. More specifically the ICAP hypothesis states that as students move up in the levels of engagement (passive to active and then to constructive and interactive) the learning outcomes are improving.

The four levels in the ICAP framework are the following:

- $\quad$ Passive learning - simply receiving educational information. Example of passive learning is watching an instructional video in a linear and passive way without any interactivity.

- Active learning - receiving information but at the same time doing something with the educational material. Example of active learning is watching a video and at the same time carrying out some activity such as pausing or rewinding the video, or doing something more active such completing knowledge testing activities and games that are related to the video content.

- Constructive learning - generating new information beyond the information that already exists in the educational material (where the educational material can be a book, online notes, educational video, etc.).

- Interactive learning - carrying out discussions and collaborative activities that are related to the educational content (e.g., related to video content).

By augmenting educational videos with knowledge testing activities, games and practice exercises that involve the use of online software, we move from passive learning to active learning (knowledge testing activities and games) and even to constructive learning (hands-on practice activities that may involve the generation of content that goes beyond the concepts covered in the video).

\subsection{Augmenting videos with knowledge testing activities}

In order to enrich educational videos with time-based knowledge testing activities, one can follow two options

a to build webpages with activities from scratch

b to use freeware or an open source software packages that are designed for such purpose. 
The latter option seems to make more sense if our aim is to build these activities faster and with fewer resources. HotPotatoes (https://hotpot.uvic.ca/) was used in our case to create interactive exercises (Figure 2).

Figure 2 The hot potatoes software suite (see online version for colours)

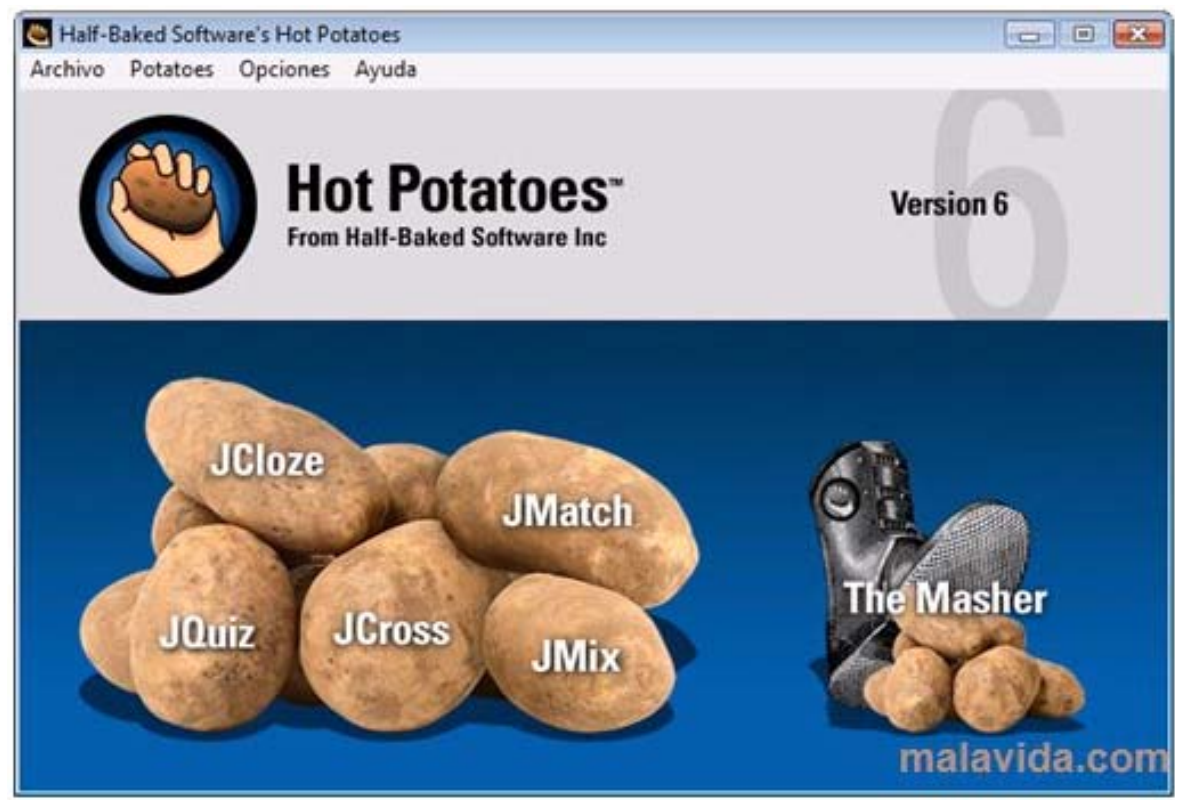

Figure 3 The event driven development environment of Gdevelop (see online version for colours)

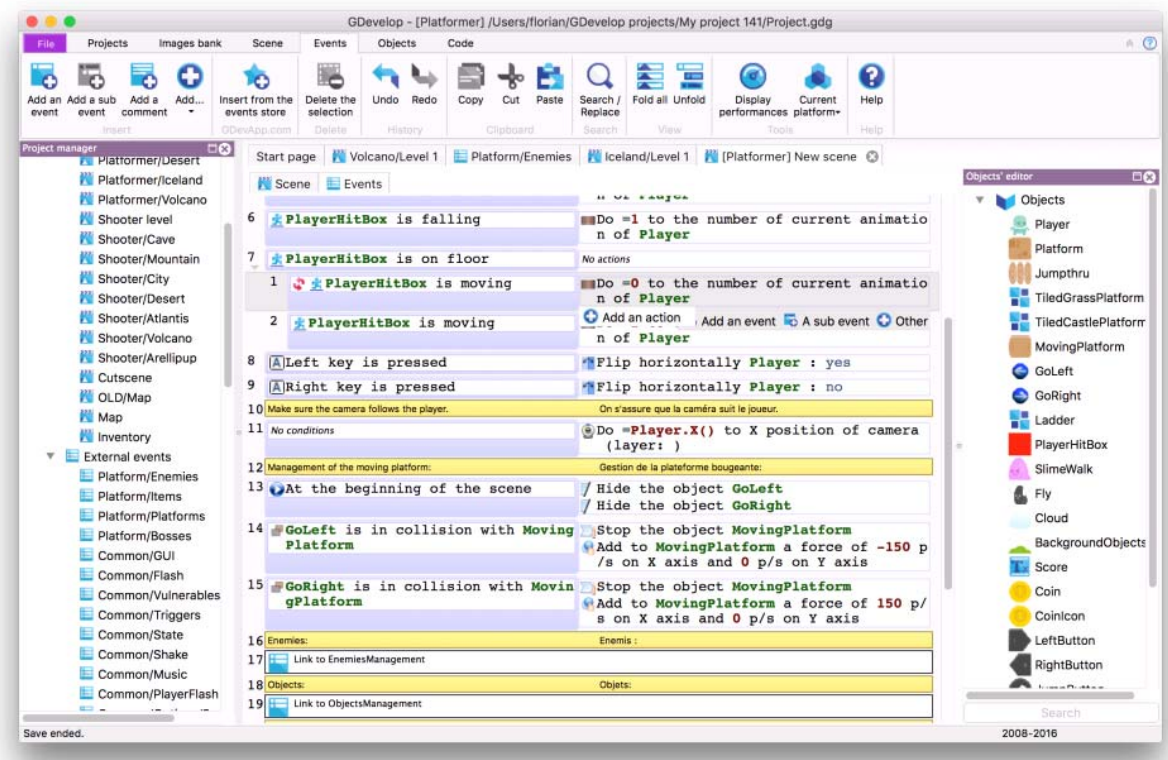


Hot Potatoes is a freeware software suite that includes six applications, enabling one to create interactive multiple-choice, short-answer, jumbled-sentence, crossword puzzle, matching/ordering and gap-fill exercises for the World Wide Web. Some of these activities can also be considered as games or edutainment activities (e.g., crossword puzzle). The activities created appear when certain points in the video timeline are reached and are always related to the video content that precedes the time of their appearance. The educator/administrator creates the activity webpages and inserts the URLs in a database together with the video-time of appearance. These URLs can then be retrieved during video run time through the MediaElement.js API and placed next to the video player in an iframe at specific time points. This is achieved using the API 'timeupdate' function. The 'timeupdate' function is fired several times in a second and through this function the playhead position is checked together with the video state (e.g., paused, playing, etc.).

\subsection{Augmenting videos with knowledge testing games}

Once again the principles described above were used in order to accompany videos with knowledge testing games. The software used for creating the games is Gdevelop (https://gdevelop-app.com). Gdevelop is an open source, cross-platform, game creation software that is event-driven and it does not require programming skills in order to develop games. The software can produce HTML5 games and also native games for all platforms (iOS, Android, Windows, Mac, Linux). Shoot'em up games were created in our case in order to accompany the educational videos. These games would appear at certain points of the video timeline in order to test upon the learner acquired knowledge and to provide instant feedback. Using Gdevelop (Figure 3) a gaming dimension is introduced to the video learning process.

\subsection{Augmenting videos with activities that require the use of online software packages}

When building interactive videos another feature that can be incorporated is the use of online software packages. For example, a training video on image editing techniques can prompt the learner to try out an image editing exercise while watching the video. An online software platform that is perfectly suitable for such task is Pixlr (https://pixlr.com).

The Pixlr platform (Figure 4) provides an array of Pixlr tools for free (Pixlr photo editor and vector editor, Pixlr express, Pixlr X) for performing image editing and vector graphics creation. Most importantly though Pixlr provides an API for communicating with the application and incorporating Pixlr functionality within other applications. Any software package that incorporates such features (freeware or open source software tools with an API for communication) is a candidate for being used in time-based activities that accompany educational videos. 
Figure 4 The Pixlr image editing environment (see online version for colours)

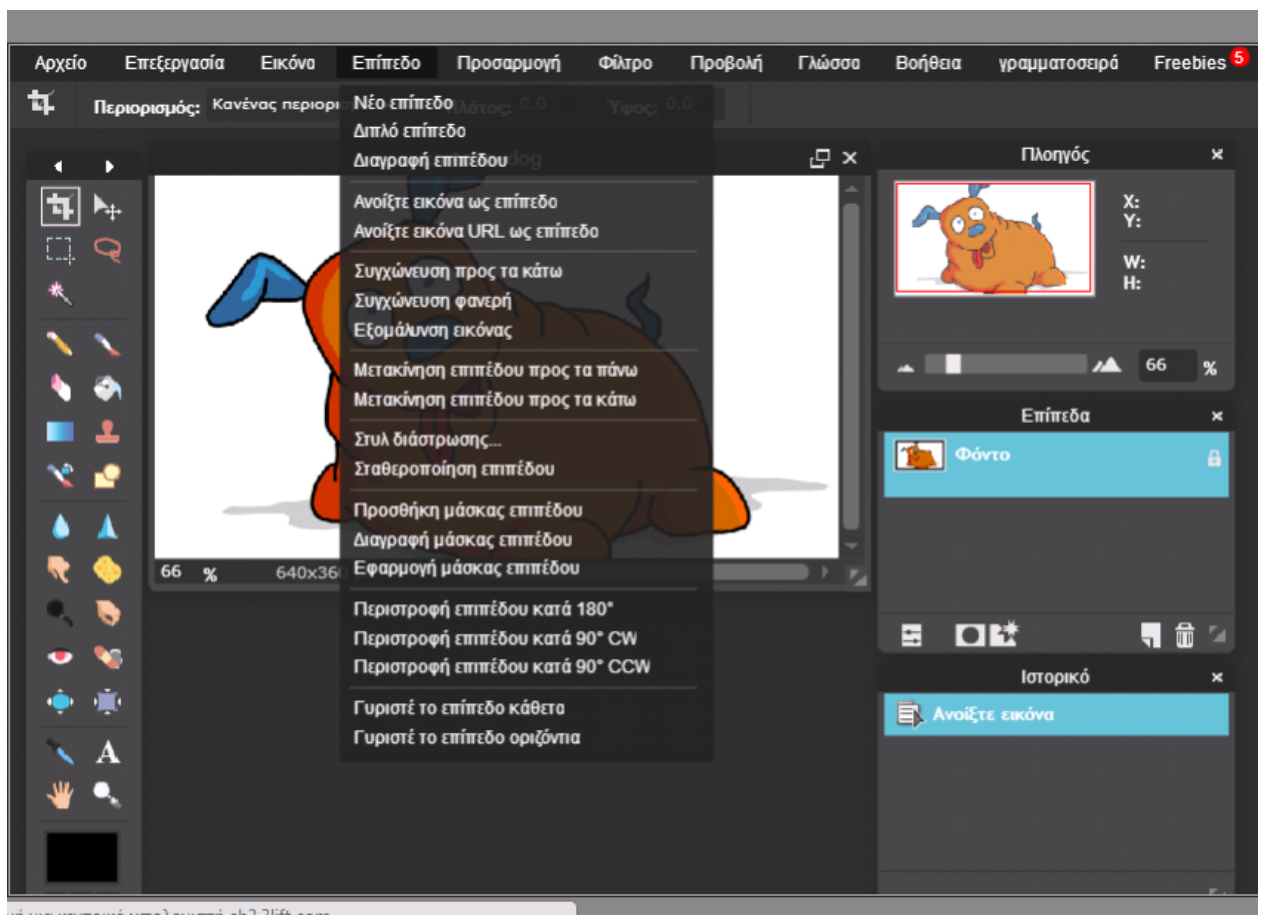

\section{Environment interface and functionality}

In the Department of Communication and Digital Media of the University of Western Macedonia, Greece (former Department of Digital Media and Communication, Western Macedonia University of Applied Sciences), a platform containing educational videos is used to support a number of courses that are part of the Department's curriculum (Introduction to New Technologies in Communication, Graphic Design, Principles of Image and Video Editing, etc.) (Figure 5).

Many of the videos hosted in the platform are enriched with interactive activities (e.g., in-video quizzes, content table, web content, and video aggregation, etc.). To access videos that are used in assignments learners are required to perform a registration procedure. When the registration procedure is completed, the student details are checked for validity by the educator/administrator and students are granted access. Then they can enter the system by entering the username and password given in the registration process. Videos that are not used in assignments can be accessed without a registration and login procedure.

The interactive options presented in the previous section are used in videos that were created as support material for a course called 'Image and Video Editing Principles'. The lesson 'Image and Video Editing Principles' is taught in the autumn semester. For the theoretical part of the course, one thematic area covered in class is audio-visual productions and more specifically the process followed in order to create videos for communicational purposes (pre-production, production, post-production). Students are 
also introduced to image and video editing software and they elaborate further on the software packages in laboratory lessons. Several videos were created to support the lesson. Amongst these videos, there is one that covers the audio-visual production stages. Another video was used for acquiring hands-on experience in image editing. This video contained seven distinct sections covering different aspects in image editing (e.g., resizing and cropping, removing background, synthesising new images, etc.). The video was later broken down into seven smaller videos in order to make video content easier to watch and comprehend.

Figure 5 Home page of the video platform where students are prompted to either carry out registration or login procedure (see online version for colours)

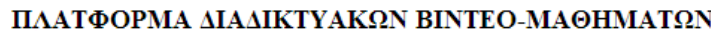

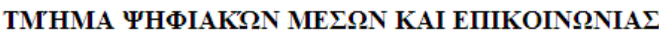

Platform of web video lessons

Department of Digital media and Communication

\begin{tabular}{|c|c|c|}
\hline 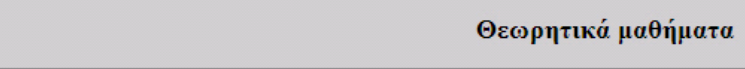 & \multicolumn{2}{|c|}{$\begin{array}{c}\text { Video lessons } \\
\text { used in theoretical lessons }\end{array}$} \\
\hline 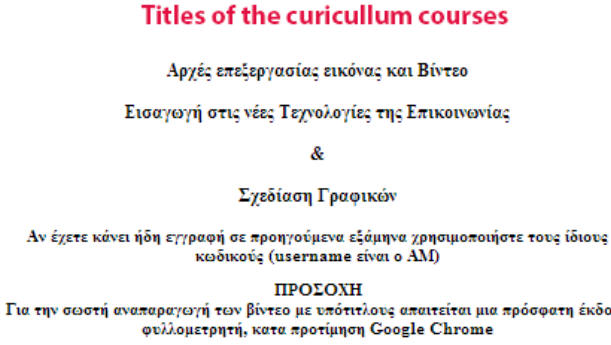 & $\begin{array}{l}\text { Links to the login promt } \\
\text { or directly to the videos in cases } \\
\text { where there is no login procedure } \\
\text { required } \\
\text { Evivon }\end{array}$ & $\begin{array}{c}\text { Links to registration } \\
\text { forms (for videos } \\
\text { where login procedure is required) }\end{array}$ \\
\hline \multicolumn{3}{|c|}{ EPГAЕTHPLAKA MAOHMATA } \\
\hline 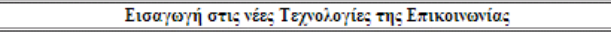 & Eúvõen & Eүrpaoin \\
\hline 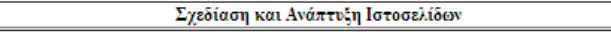 & 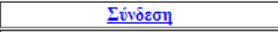 & Eypooví \\
\hline 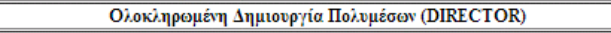 & 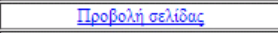 & \\
\hline 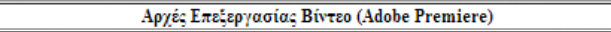 & 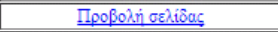 & \\
\hline 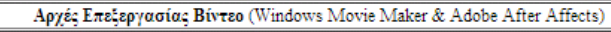 & 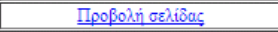 & \\
\hline
\end{tabular}

Note: Three courses can also be accessed without a login procedure.

The first video that contained information on audio-visual productions was augmented with knowledge testing activities created in Hotpotatoes and games created with Gdevelop as explained in the previous section. This will be referred to as Video environment 1 for the rest of the paper. The video covering image editing techniques was enriched with image editing exercises so students could practice with an image editing software as they watch the video in an integrated environment. This environment will be called video environment 2. Details of the two environments follow in the next two subsections.

\subsection{Video environment 1. Audio-visual production stages}

The video used in this environment was created by a student with experience in audio-visual productions as part of his dissertation. The student worked for a company involved in audio-visual productions and more specifically in creating promotional videos for companies and organisations. The video that he created explains in detail the 
stages followed for producing promotional videos (pre-production, production, post-production). The video also contained interviews with professionals working in the area (scriptwriters, directors, video editing professionals). The video length is 30 minutes. The video was augmented with time-based exercises created with hot potatoes and knowledge testing games created with GDevelop. More specifically hot potatoes was used to create fill-in blanks, multiple choice, matching, and crossword puzzle exercises. Thirteen exercises were created in total using Hot Potatoes (e.g., Figures 6, 7, 8 and 9).

Figure 6 Fill in the blanks exercise (see online version for colours)

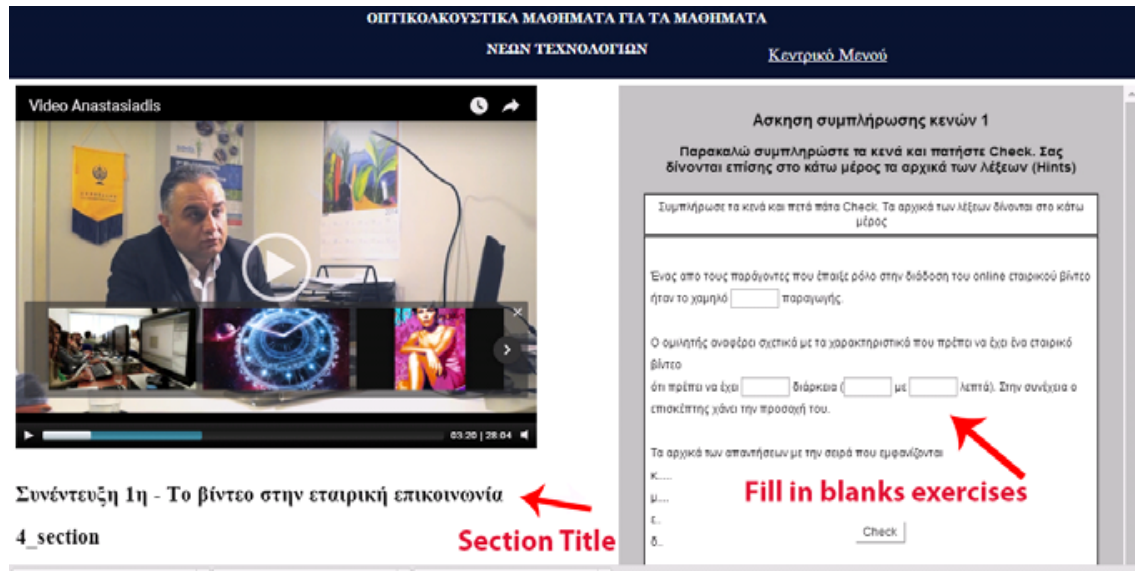

Figure 7 Matching exercise (see online version for colours)

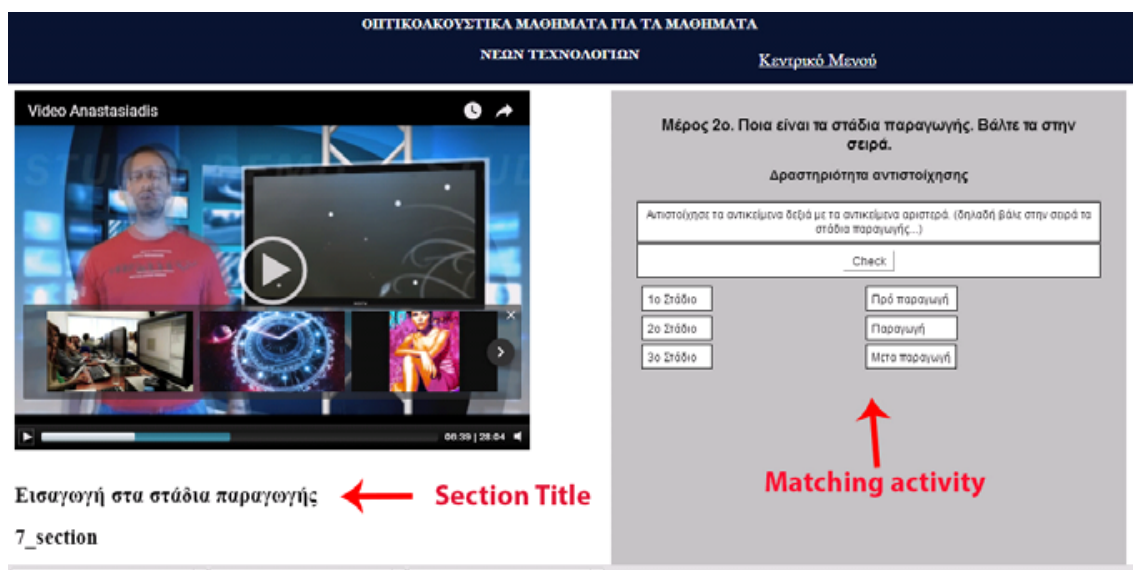

Similarly, Gdevelop was used to create three Angry Birds shoot'em up games. In these games

a a question is shown on the game stage (in green background)

b angry birds with different labels (answers) and appearance are moving along the stage

c learners are required to shoot the bird with the correct label (e.g., Figures 10 and 11). 
Figure 8 Crossword puzzle (see online version for colours)

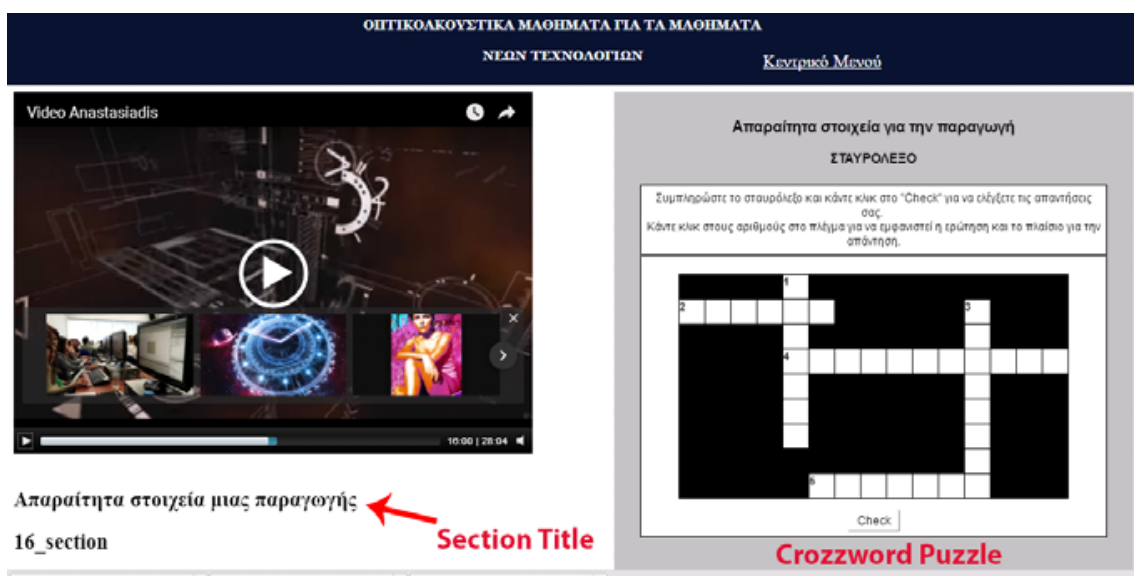

Figure 9 Multiple choice exercise (see online version for colours)
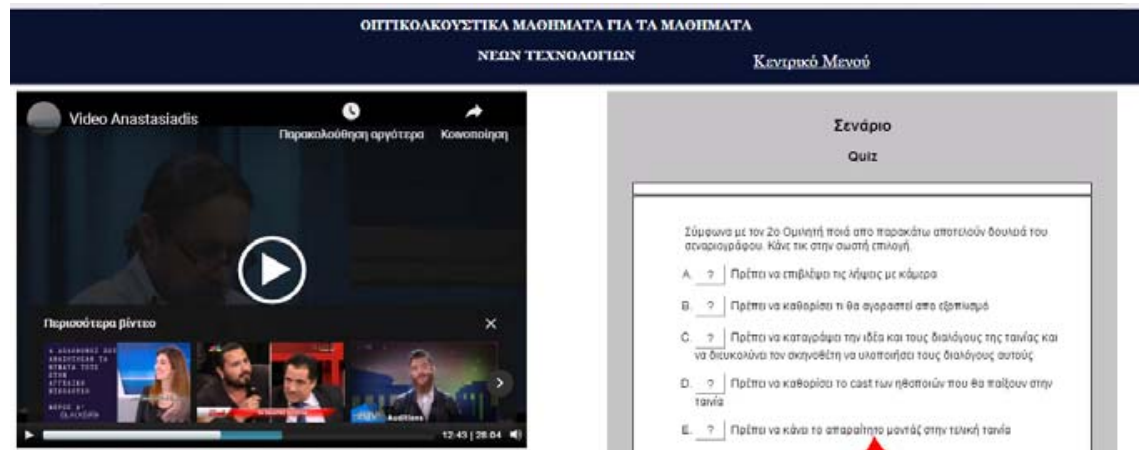

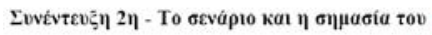

13_section

Section Title

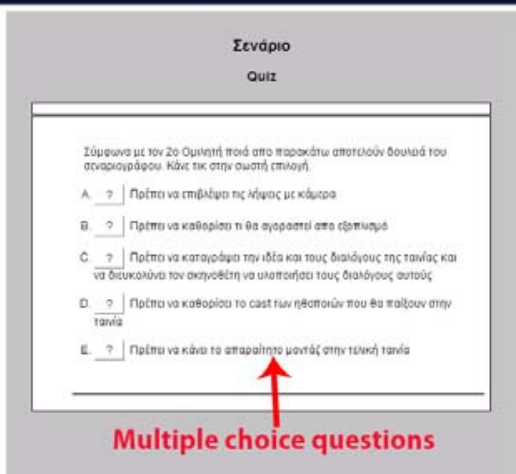

Figure 10 Angry birds shoot'em up game (see online version for colours)

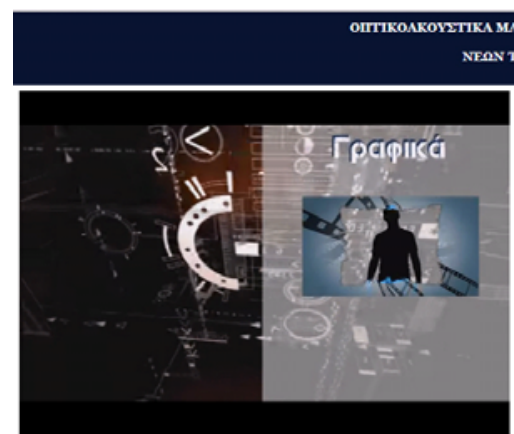

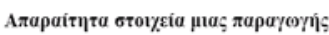
15 section

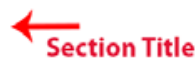

Kextousó Mtswoí

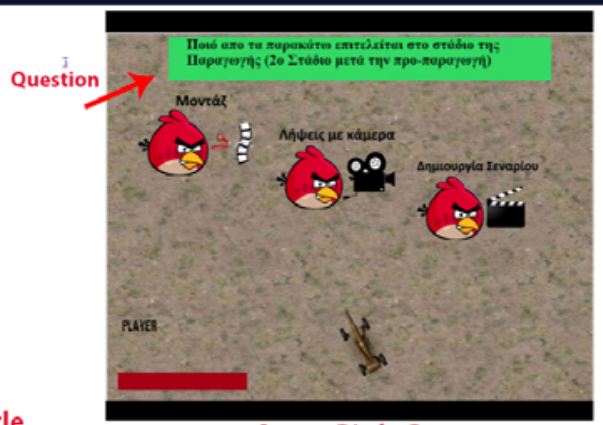

Angry Birds Game 
Figure 11 Angry birds shoot'em up game (see online version for colours)

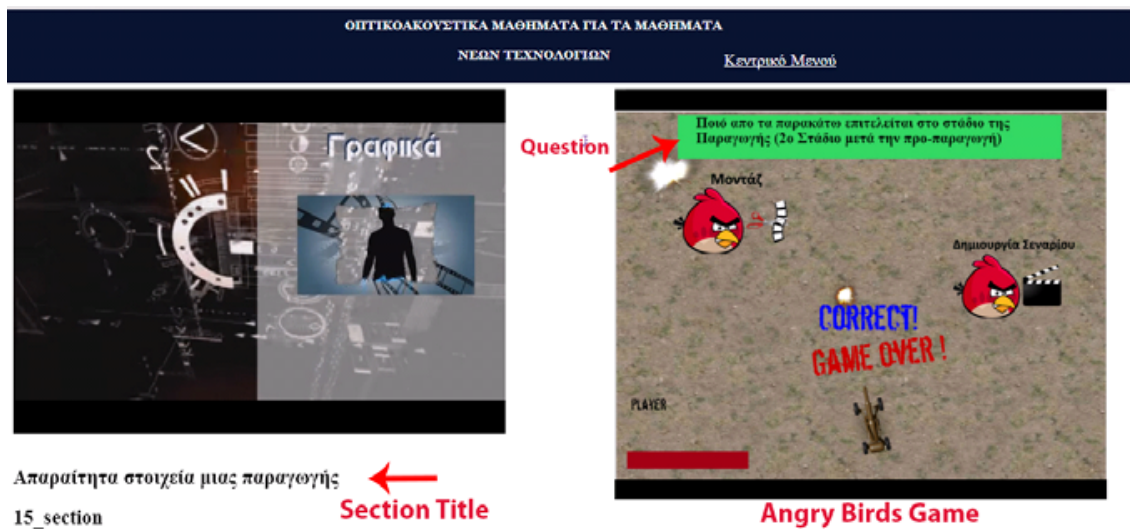

The games and exercises appear at certain points of the video (defined by the educator) and next to the video player in an iframe. The video pauses when these points are reached. In every activity (exercise or game) the learners are informed whether their answers are correct or not with appropriate feedback.

\subsubsection{Additional features - storing exercise and game results and activity table}

In the described environment the learner scores for each activity are stored in the database. More specifically for the Hot Potatoes exercises, this is achieved by modifying the script produced by the software and by calling a PHP program to carry out the insertion of the scores in the database. Similarly, with Gdevelop a routine calls a PHP program upon game completion in order to insert the score in the database. For the Hot Potatoes exercises the learner is given the chance to perform the exercise again if the exercise is not completed successfully. This option was not initially present for the Angry Birds games and the games would end after shooting the right or wrong bird. However, the option to try again after an unsuccessful attempt was incorporated on the way after taking into account the comments of students that used the environment. If an activity (exercise or game) is completed successfully then this activity does not appear again. Instead, at the specific time point (where the activity would normally appear) a message appears informing that the activity is completed.

The learner can also obtain a detailed report of his/her achievement at any time by clicking at a relevant link placed under the video player (Figure 12). This report presents the exercise titles, the exact video time point of each exercise, the score achieved for each exercise as well as the overall average score obtained from all the exercises. In the case where there were more attempts in one exercise (a typical scenario) then the score for the exercise would be calculated from the average of all attempts. Moreover, the learner is provided with an activity table with direct links to the activities. If the user wants to get back to an uncompleted activity then he/she can do so by using the activity table. This is simpler than using the video slide bar in order to get to the uncompleted activities. 
Figure 12 Table containing direct access links to the activities (links on the left) and a link to check the score acquired for every completed activity as well as the overall score (see online version for colours)

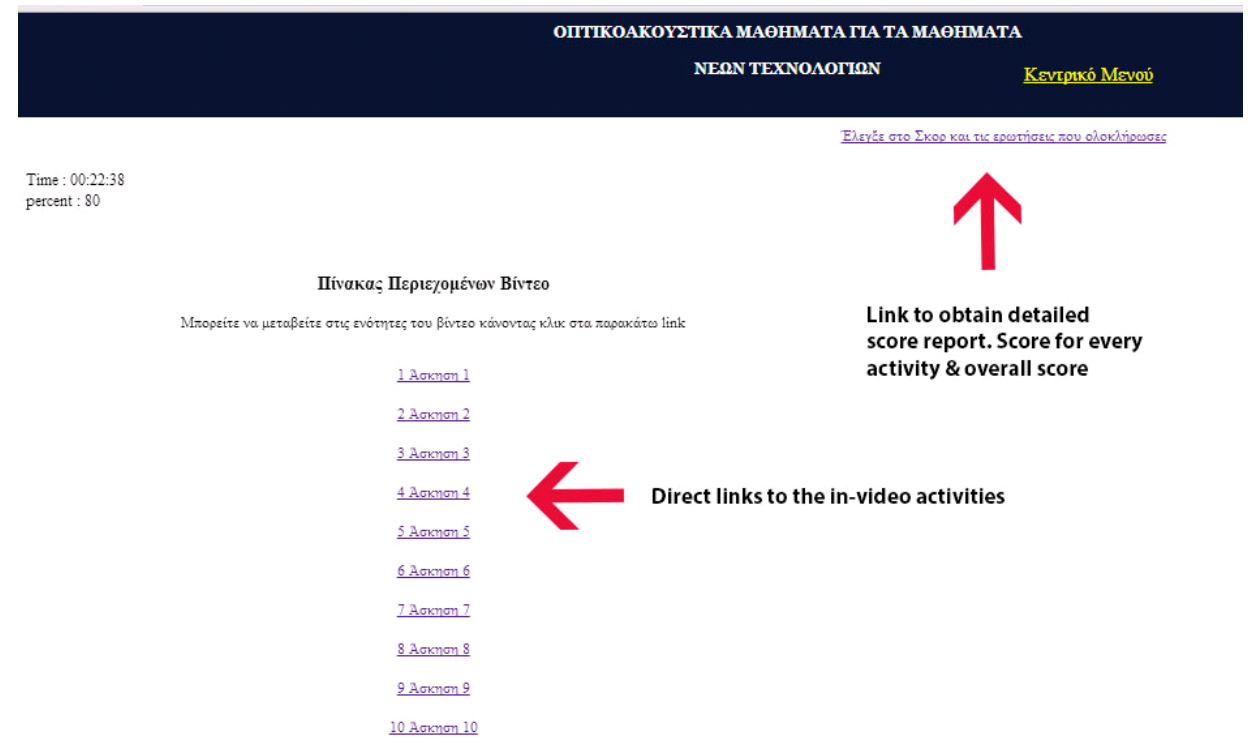

\subsection{Video environment 2. Video training tutorial on image editing techniques}

As already mentioned the video used in this environment covers aspects of image editing. Students that used this environment to complete the assignment were told to read a web page with brief instructions on how to use the environment. In the application interface, the video occupies the top of the page and under the video, there is an area with a table of contents (on the left) with links to different topic sections. Sections were created by a logical segmentation of the video content (segments that cover particular subtopics). The video lesson on image editing was initially divided into seven logical sections and the starting points of these sections were stored in the database. The first section is a general introduction to Pixlr and the six sections that follow present different image editing techniques (e.g., resizing, cropping, synthesising a new image from other images, removing the background from an image, removing parts from the image, applying filters, etc.).

The techniques are presented by descriptive exercise implementations. An extra dummy section was also defined (or marker point) in the end in order to provide a link (in the table of contents) to the end of the video. On the right side of the webpage and under the video there is an area where exercise descriptions appear together with links. Learners have to follow the links in order to complete the exercises. Each exercise (six in total) is associated with a different section and appears only during that section. Students are prompted to follow the link at specific points during video execution. When the link is followed the Pixlr environment opens in a different browser window (or tab) together with the related image files that are needed in order to complete the exercise. Although Pixlr could also be opened as a separate iframe in the same webpage and next to the video lesson, this option was not followed in order to give enough browser space to the 
video (and the application) so the learner can have a clear view of the actions carried out in the Pixlr image editing environment. After completing the exercise, the learner can save his/her work by pressing the 'Save' menu item in Pixlr. The image file of the completed exercise is then saved in the learning environment web server and not in the students computer (or the students account on the Pixlr web server). This is achieved by using the Pixlr API. This option was chosen since students would have to deliver the same exercises as part of an assignment and cheating had to be avoided. By having students use their accounts to view the videos and complete the exercises the chances for cheating would be reduced. Moreover, video viewing and assignment delivery is accomplished in an integrated environment. Learners were able to view the stored files whenever they wanted by pressing on a relevant link on the environment interface. Amongst the instructions, it was mentioned that images above 1,000 width or 1,000 pixel height would not be stored on the server and that was done in order to avoid delays and storage problems. An image with a relevant informative message was saved in case the student attempted to save an image that exceeded these dimensions.

Figure 13 Environment used for supporting a training course in image editing (see online version for colours)
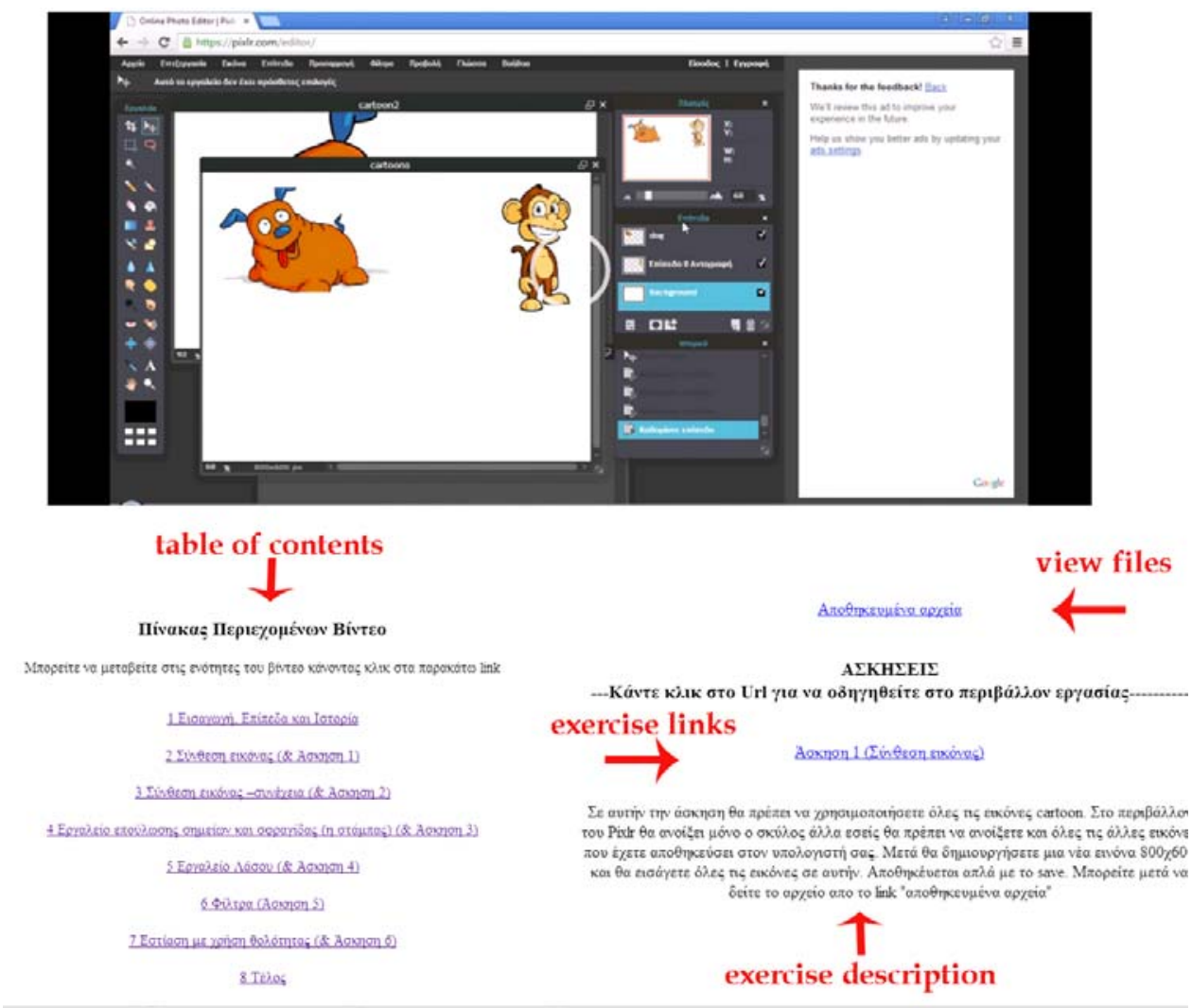

The video was later broken in seven short videos (each section became a separate video). Either by dividing the video into distinct separate sections and introducing a content table to access these sections, or actually breaking the video into smaller segments, the 
segmenting principle is fulfilled. The breakdown of multimedia in logical segments is supported in the literature as a way to make multimedia learning more effective. According to Mayer (2005), the segmenting principle states that people learn more deeply when a multimedia message is presented in learner-paced segments rather than as a continuous unit.

At this point, it is worth mentioning that the environments covered in this section contain an activity tracking module that is responsible for storing all learner interactions in a database. Learner viewing and activity data can be used for behavioural analysis (learning analytics) purposes. A detailed description of the module is given in Kleftodimos and Evangelidis (2016b).

\section{Experiences gained from using the environments in classroom settings and evaluation}

The environments that were described in detail in the previous section (i.e., 4) for supporting the course 'image and video editing techniques' were used in subsequent years for the completion of assignments. The assignments were optional and would count towards the students' final mark.

\subsection{Video environment 1}

This environment was first used in the winter semester of the academic year 2017-2018. The environment consisted of a video (related to audio-visual productions) and 16 in-video activities: five fill in the blanks, three matching, three multiple choice, two crossword puzzle, and three angry bird shoot'em up games as explained in Section 4.1. Besides the video environment (video enriched with activities) the platform also contained a pre-test, a post-test and an evaluation questionnaire. The pre-test was set up in order to measure the students' knowledge on the topic before viewing the video and carrying out the in-video activities. Similarly, the post-test intended to measure student knowledge after the intervention.

Figure 14 Main menu - pre-test, video, post-test, and evaluation (see online version for colours)
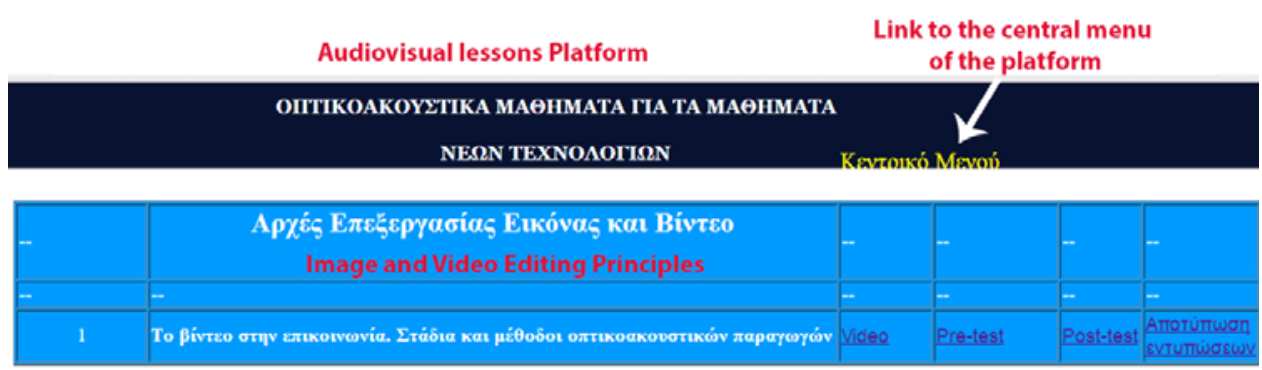

Video in communication. Production stages

Links to video, Pre-test, Post-test and evaluation questionaire

As mentioned the platform content could be accessed after a login procedure. Login credentials could be obtained after a registration procedure and upon educator permission. The registration procedure required students to enter some personal 
demographic details, their student id and a password of their choice. The final permission to access the platform content was granted by the educator after checking the student information. After logging in the system students encountered a webpage with four links (Figure 14). A link to the video environment, a link to the pre-test, a link to the post-test and a link to the evaluation questionnaire. The questionnaires would be activated at appropriate times during the process.

The sequence of events would be as follows:

a first the students would complete the pre-test

b then they would start viewing the video and complete the in-video activities

c then they would complete the post-test

d finally they would complete a questionnaire in order to evaluate the features of the interactive video environment.

The whole process was carried out and tested by the course educator and a small number of students (i.e., five students) before given out to the students that took part in the assignment. This was done in order to spot system errors and misunderstandings. The questionnaires, video and in-video activities were also validated by another educator specialising on multimedia topics in order to make sure that the questions are comprehensive, appropriate for the sample population (first-year students with little or no knowledge of the concepts covered in the video), and addressing aspects that are covered in the video.

\subsubsection{Participants}

The students that wanted to take part in the optional assignment were split into groups of 17-20 and were asked to come to a specific lab at scheduled times with their own set of headphones. A total of 92 students (43 male and 49 female) turned up for the academic year 2017-2018 in order to complete the assignment. It was communicated to the students that three things would count towards their mark: their participation $30 \%$, the average overall score in the time-based activities $30 \%$, and the mark obtained in a post-test $40 \%$.

The educator (and researcher) of the course was in the lab during the whole time of the process. The environment and process details were explained by the educator at the beginning of the session. Students were also able to address questions to the educator regarding the environment and the sequence of events at any time throughout the process. Students performed the registration procedure without problems and logged in the platform by entering their login credentials. After login they encountered the links of Figure 14. Students were told that the available time for completing the whole process was 1 hour and 30 minutes.

\subsubsection{Pre-test, video with activities post-test and evaluation of the environment}

The pre and post-test questionnaires were created with Google Forms. The pre-test contained 13 multiple choice questions. The post-test contained all 13 questions of the pre-test plus one more. During the process, the students were asked to provide their student id and name both in the pre-test and the post-test. None of these questions were directly related to the in-video exercises. The evaluation questionnaire was completed 
anonymously so students could freely express their opinion about the environment. The evaluation questionnaire contained four closed-ended questions that aimed at recording

a student overall satisfaction

b the level of difficulty in completing the interactive activities

c the perceived efficiency of the in-video activities in learning

d the level of enjoyment associated to the activities.

There was also an open question for the students to comment freely on the overall experience (what they liked or disliked, what impressed them and if there was something that they would change etc.).

After a short explanation of the environment and procedure details, the educator activated the pre-test questionnaire in order to accept responses and asked the students to perform the questionnaire. After completing the pre-test the students were free to start the video and complete the in-video activities. In the meanwhile the educator checked upon the responses and ensured that the pre-test was completed by all students. After completing the pre-test the students continued to complete the rest of the steps in their own time and pace. The post-test and evaluation questionnaires were opened for responses at appropriate times by the educator. Students were able to check if they completed all the in-video activities, the score obtained for each activity as well as their overall score by pressing at an appropriate button on the environment interface as explained in Section 4 (Figure 12).

\subsubsection{Outcomes}

Regarding the pre-test the outcomes showed that the students were able to answer some questions with success. However, this success was due to the fact that these questions could be answered based on logical assumptions. On the other hand in most questions the large majority of students were not able to give correct answers and thus it is assumed that the students possessed very little knowledge concerning the concepts presented in the video. During the assignment, a number of students showed enthusiasm and completed the assignment without major difficulties while others seemed to get tired due to the video duration (30 minutes) and the number of activities (16 exercises). It was known to the educator (and principal researcher of the paper) that the number of activities was indeed high but the process was not targeting solely on student satisfaction. The aim of the process was also to carry out an assignment which would count towards the course final mark and thus it made sense to raise the level of difficulty. Students who took part in the assignment had as mentioned an 1 hour and 30 minutes limit to complete the assignment and this time interval was proven to be sufficient for all students to complete the assignment.

As mentioned all questions in the pre-test existed also in the post-test (13 questions) and for these questions the results showed an average of $22 \%$ increase in the questions that were answered successfully (3.9 minimum and 59.6 maximum). As mentioned, a small number of questions could be answered based on logical assumptions and for these questions the students performed well on the pre-test and thus the overall increase was small. For the rest of the questions though the increase was much larger. Of course, this result does not reveal whether this increase is attributed to the active way of learning and 
in order to compare the learning outcomes between active video viewing to passive video viewing the authors plan to carry out similar experiments (same conditions and sample size) in which students would be asked to complete the same process (as part of an assignment) but without the in-video interactive activities.

Figure 15 Evaluating the environment, academic year, 2017-2018 (see online version for colours)

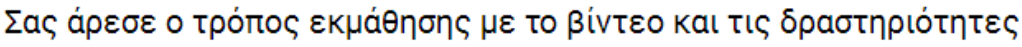 (}

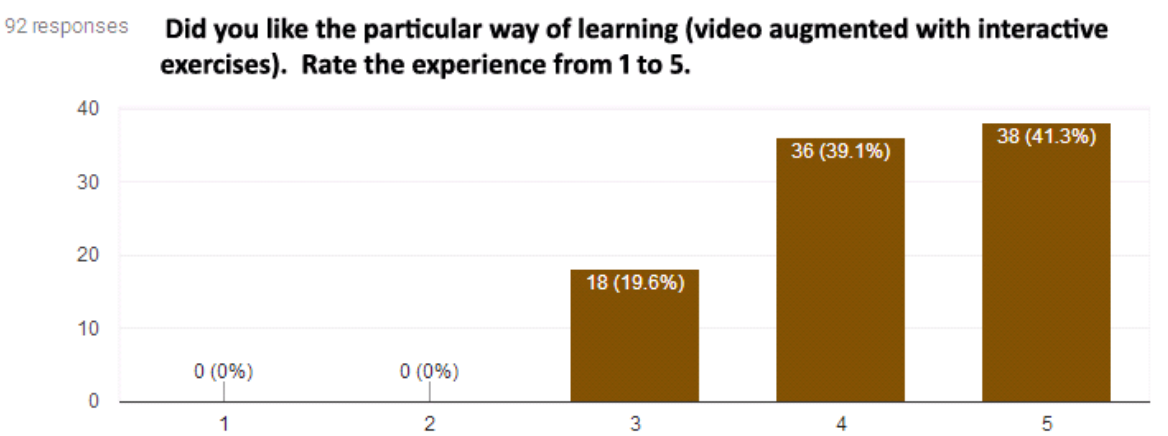

The results of the evaluation questionnaire showed that students evaluated the environment positively. In order to test the reliability of the evaluation questionnaire, the internal consistency of the four close-ended questions was calculated based on Cronbach's alpha. Cronbach's alpha coefficient value was 0.625 which is acceptable for exploratory researches that do not aim to validate existing scales.

In the first question of the evaluation questionnaire students were asked to rate their experience from using the environment using a $1-5$ scale. $19.6 \%$ gave score $3,39.1 \%$ score 4 and $41.3 \%$ score 5 . The results are given in Figure 15.

Figure 16 Rating the level of difficulty (see online version for colours)

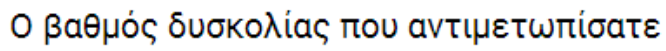

92 responses

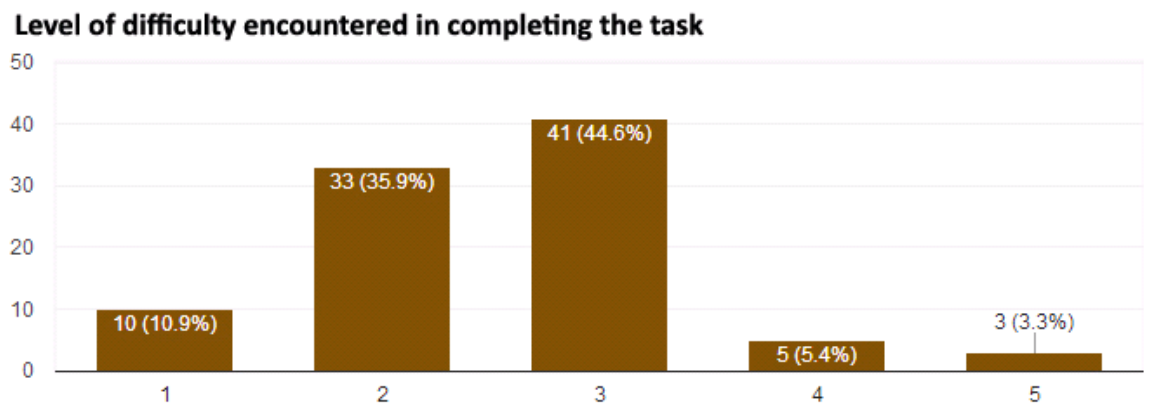

In the second question the students were asked to rate the level of difficulty in using the environment and completing the in-video activities. The results were again satisfactory. In a 1-5 scale where 5 was 'high difficulty' most students rated the level of difficulty of 
the activities as average (e.g., $44.6 \%$ gave score 3 ) or below average (35.9\% gave score 2 and $10.9 \%$ score 1). The results are given in Figure 16.

Figure 17 Would a video with out interactive activities be equally efficient in learning (academic year 2017-2018)? (see online version for colours)

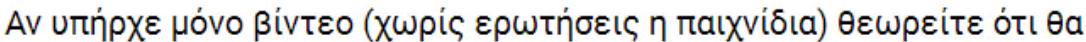

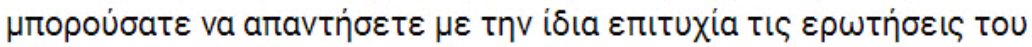

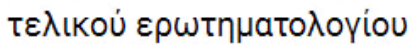 \\ 92 responses
}

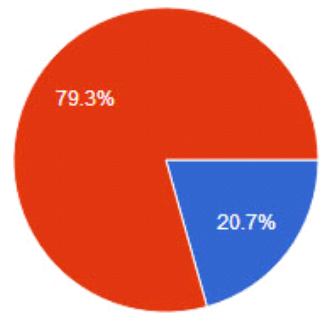

Nal Yes
Oxl No

\begin{abstract}
if there was only a video (without exercises nor games) do you think that you would answer the questions in the final questionaire with the same success?
\end{abstract}

In the third question students were asked to state if they believe that they would perform as well in the post-test if the video was not accompanied by the in-video activities. $79.3 \%$ of the students gave no for an answer (Figure 17). If these perceptions however reflect the reality is something that remains to be validated.

When students were asked to evaluate the activities they evaluated some better than others. For example, the crossword puzzles were high in their preferences while the angry birds shoot'em up games and the fill in the blanks exercises were evaluated lower especially amongst the first groups that completed the assignment. This was a surprising result especially for the shoot'em up games. By examining the comments given in the evaluation questionnaire and through talks with the students after the experiment and during lecture hours it became evident that the low evaluation score for the games was attributed to the design of these activities as well as the required difficulty in giving the correct answers (shooting the correct birds). For example, the angry birds games did not give students a second chance in case of failure. Also, the questions presented in two of the three games were according to the students hard to answer and this was a reason for giving a low evaluation rank. Some students also said that they evaluated the angry birds' activity low for other reasons such as variations in the volume of the sound during the activity (a clapping sound that occurred after a successful attempt was louder than the video narration and music audio). However, the majority of students agreed that the angry birds games were a very good and entertaining feature and that the games should remain in the environment if the issues mentioned were dealt with.

As far as the fill in the blanks exercises are concerned some of these were not designed properly and did not count a slightly different answer (the same word in plural, in capital letters, accented in a different letter, etc.). This was again a reason for giving a low evaluation rank. Also, few students had dyslexia although we think that this did not pose problems as these students were provided with the necessary assistance by the educator who was in the lab organising and inspecting the whole procedure. When the 
reported deficiencies were corrected then the student satisfaction showed an increase and these activities were evaluated higher. The final results are depicted in Figure 18.

Figure 18 Evaluating the activities (see online version for colours)

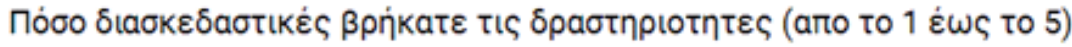 How entertaining did you find the activities (from 1 to 5)?}

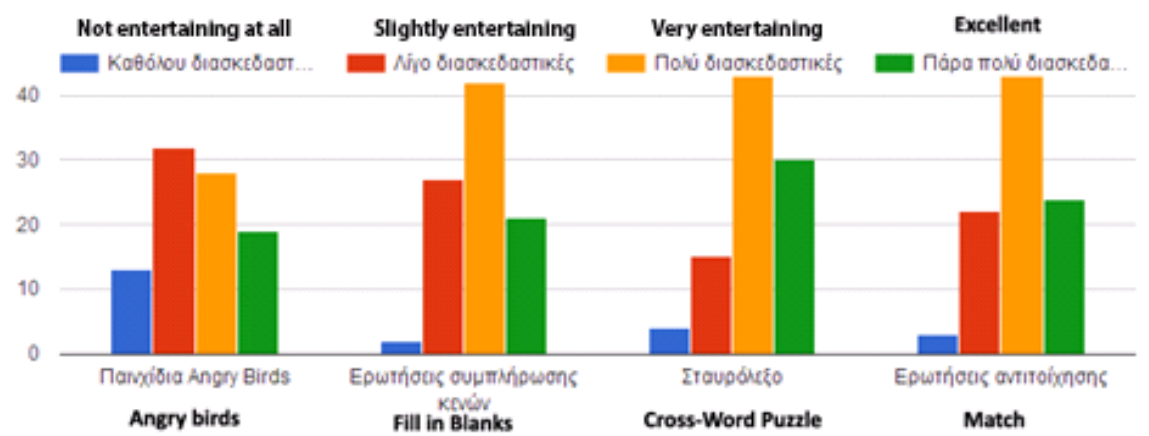

The same procedure was repeated in the winter semester of the academic year 2018-2019. 95 students took part in the assignment, all of the students completed the pre and post tests but only 93 answered the questions of the evaluation questionnaire. This time a smaller number of activities was included in the video. More specifically, 10 activities were incorporated in the video: 2 fill-in blanks exercises, 2 match exercises, 2 multiple choice, 1 crossword puzzle, and 3 angry birds shoot'em up games. The results are still being processed in order to check the knowledge gain between the pre-test and the post-test but what is certain is that the new environment which contained fewer activities and was updated according to student recommendations and error detections, had a better impact on the student overall satisfaction. The increase in student satisfaction is obvious when comparing the graphs in Figures 15 and 19.

Figure 19 Evaluating the environment, academic year, 2018-2019 (see online version for colours)

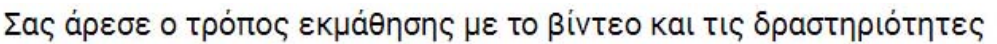

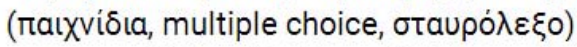
93 responses Did you like the particular way of learning (video augmented with interactive
exercises). Rate the experience from 1 to 5.

60

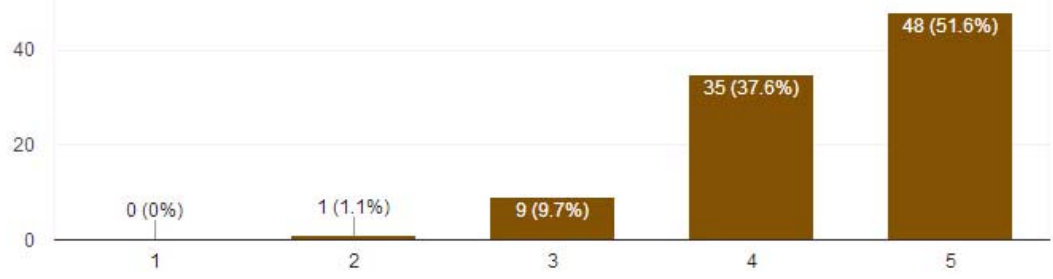

Another observation is that this time an even larger percentage of students thought that a video with interactive activities is more effective in learning than a plain video. More 
specifically in the question asking if they believed that they would perform as well in the post-test if the video did not contain interactive activities, $87.1 \%$ gave 'no' for an answer (Figure 20). The percentage of students that gave no for an answer in the previous academic year was $79.3 \%$.

Figure 20 Would a video with out interactive activities be equally efficient in learning (academic year 2018-2019)? (see online version for colours)

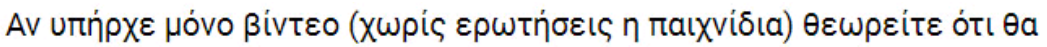

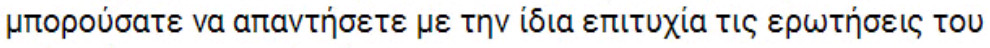

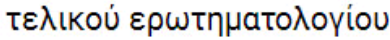 \\ 93 responses
}

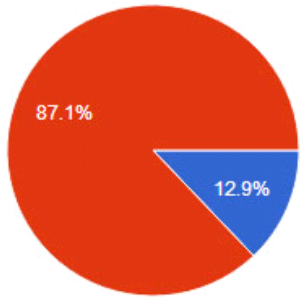

\begin{abstract}
if there was only a video (without exercises nor games) do you think that you would answer the questions in the final questionaire with the same success?
\end{abstract}

As mentioned earlier there was also an open-ended question in the evaluation questionnaire where the students could leave comments about the environment features as well as the video educational quality. They were also asked whether they would change anything in the environment if they could. Most of the student comments were positive. Below we give examples of such comments gathered in academic years 2017-2018 and 2018-2019.

\subsubsection{Student comments}

"Everything was fine. I gained new knowledge while being entertained. This method of teaching is very interesting and helps in learning and keeping things in memory."

"Although the video contained difficult concepts, the fact that it was combined with activities made it easier to understand without tiring the student."

"I wouldn't change anything. I enjoyed the whole process a lot."

"I was impressed by this method of learning and I would be willing to try it again Excellent work."

"It's the first time that I come across such kind of learning application. Very interesting way of learning."

"I was impressed by everything. The video and the activities. Everything was new to me."

Besides the positive comments there was also a small number of students that expressed complains about the video length and difficulty of the activities. 


\subsection{Video environment 2}

The video environment 2 that was described in detail in Section 4.2 was used in the winter semester for four consecutive academic years. These academic years were 2015-2016, 2016-2017, 2017-2018, and 2018-2019 although the data from the last academic year was not processed by the time that this paper was written. The environment was used for class assignments and before making the environment available to the students it was tested by a small number of people (students not included in the sample) and another educator that also teaches image editing to check whether the environment features, instructions, and tasks to be carried out were comprehensible. The assignments again counted towards the overall mark. During lab lessons, students are taught image and video editing techniques with Photoshop and Premiere. The aim of the assignment was to get the students acquainted with another image editing program, that of Pixlr. Students were asked to complete the assignment at their own time and within a certain time period (e.g., two weeks) using either their own home computers and laptops or alternatively by using the computers at the University library. Students completed the exercises while watching the video sections (or the seven videos) and the exercises were marked by the educator. Students were also asked to evaluate the environment after completing the assignment as well as the difficulty of the image editing exercises. The evaluation questionnaires were not identical in all the academic years and the questionnaires were not answered by all the students who completed the assignments. 60 students took part in the survey for the academic year 2015-2016. The survey was created with Google forms.

In a question if the video environment (enriched with Pixlr activities) was user friendly $60 \%$ stated that it was and they used it without difficulty (Figure 21, red part of the pie diagram), $40 \%$ stated that it was satisfactory and they did not have major difficulties in using the environment (blue part of the diagram) while none of the students stated that they encountered major difficulties.

Figure 21 Environment evaluation, academic year 2015-2016 (see online version for colours)

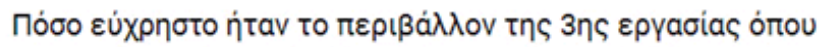

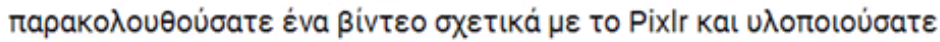

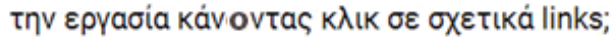

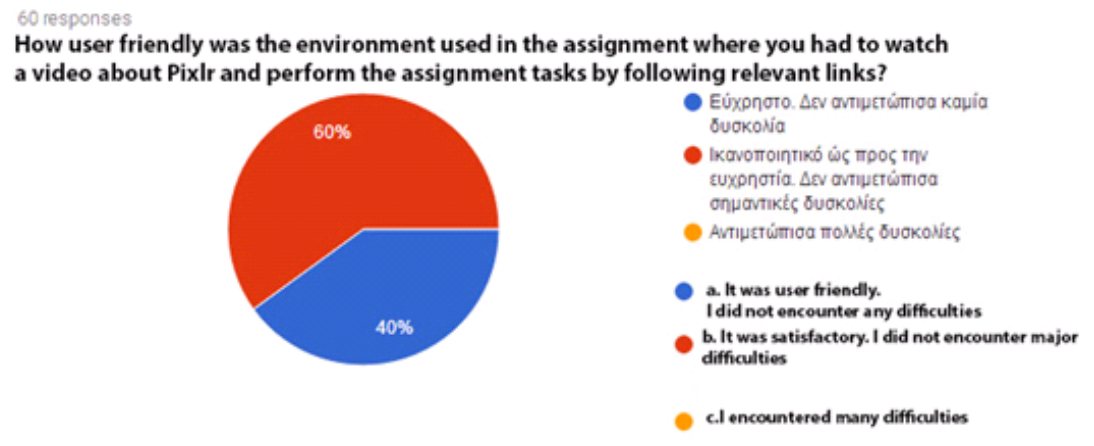


Very similar results were obtained in 2016-2017 when the environment was again evaluated (72 responses, Figure 22).

Figure 22 Environment evaluation, academic year 2016-2017 (see online version for colours)

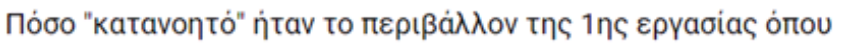

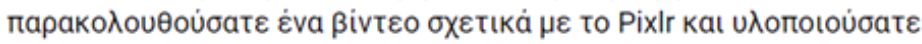

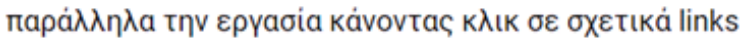

72 responses How "understandable" was the environment used in the assignment where you had to watch a video about Pixlr and perform the assignment tasks by following relevant links?
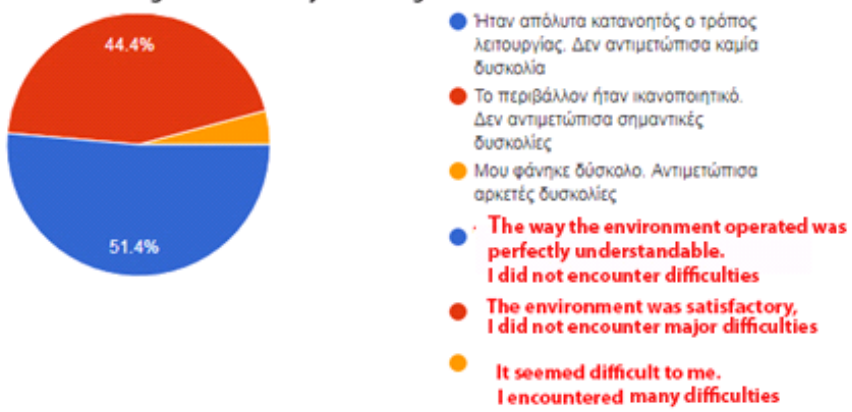

More specifically $51.4 \%$ of the students stated that the environment was comprehensible, and that they used it without difficulty (blue part of the pie diagram), $44.4 \%$ stated that it was satisfactory and they did not encounter major difficulties (red part of the diagram) while only a small percentage of $4.2 \%$ stated that the environment was difficult to use and they encountered many difficulties (yellow part).

Equivalently 68 responses were obtained in 2017-2018. The evaluation questionnaire was slightly different for that year. In that year, the video (with seven sections) was broken into seven smaller videos. Students were asked to evaluate the environment in a 1-5 Likert scale and the results are depicted in Figure 23. Most answers are between 4 and 5 .

Figure 23 Environment evaluation, academic year 2017-2018 (see online version for colours)

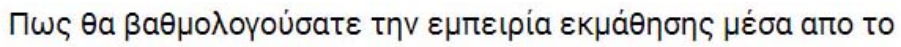

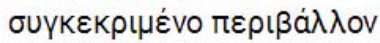

68 responses

How would you evaluate the learning experience from using the environment (from 1 to 5 )?

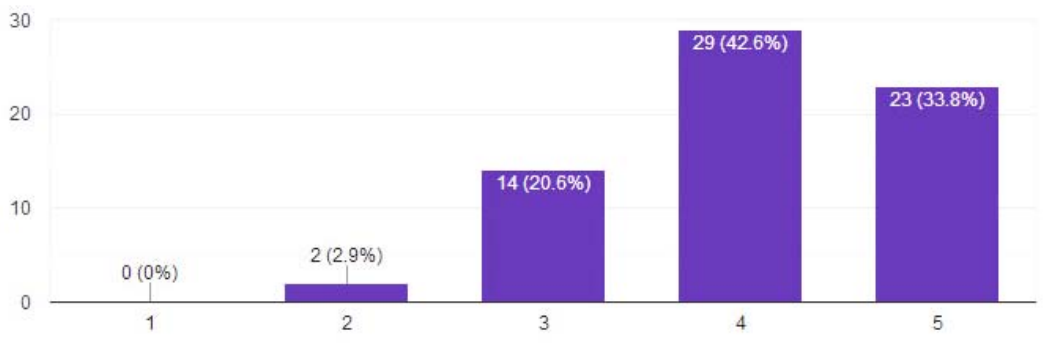


Furthermore in 2015-2016 students were asked whether educational videos are more suitable for supporting theoretical aspects (e.g., audio-visual production stages) or for supporting more practical aspects such as teaching software packages (e.g., image editing with Pixlr). $78 \%$ of the students answered that video can be used successfully in both cases, $18.6 \%$ that it is more suitable for teaching the usage of software packages and $3.4 \%$ that it is more suitable for teaching theoretical aspects. Results are depicted in a pie diagram in Figure 24.

Figure 24 In which cases is video more suitable? For teaching theoretical aspects or more practical ones (e.g., image editing with Pixlr) (see online version for colours)

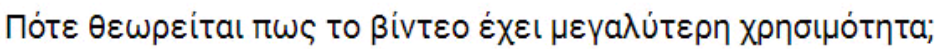
59 responses

Where do you think that video is more useful?

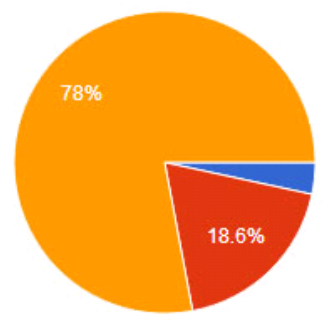

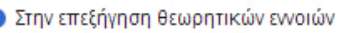

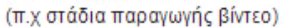

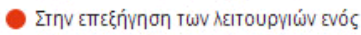

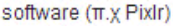

Kal ora 2

a. In expla ining theor etical a spects

(e.g. audiovisual production stages)

b. In explaining how a software package works (e.g. Pixlr)

c. Both

\section{Conclusions}

The aim of this paper was to present video-based learning environments enriched with interactive knowledge testing activities, games, and software practice exercises. Videos today are mainly linear and their viewing is passive. In cases where interactive features are encountered these are mostly confined to in-video quizzes and annotations. This paper attempts to introduce new ways of interactivity in video-based learning and it is anticipated that the solutions presented will provide educators and e-learning developers with ideas for creating innovative interactive video environments. The solutions presented are also cost efficient since only open source and freeware packages are used in the development of the interactive video environments. The interactive video environments were also used in educational settings. The way these environments were integrated into the academic curriculum is also presented in the paper as well as experiences gained from using the environments. More specifically two video environments were built for supporting the theoretical and practical part of a course named 'image and video editing principles'. The video environment aimed at supporting the theoretical part was augmented with knowledge testing activities and games. The Hot Potatoes software was used for building a series of activities and GDevelop for building games. Mediaelement.js (an open source HTML5 video player) was used for synchronising the video content with the activities in order to create time-based interactive videos. The second environment was created for supporting the practical part of the course. Students could watch a video demonstrating image editing tasks using an online software package and at the same time they could perform similar activities in an 
integrated environment. The software that was incorporated into the environment is Pixlr an online image editor. The Pixlr API was used for incorporating the software tool within the video environment.

The students also evaluated the environments and an attempt was made to capture the knowledge gain from using one environment (video enriched with Hot-Potatoes activities and games) with the use of pre and post-tests. However, the main focus of the paper is on presenting alternative ways for creating interactive videos (as well as technical details on how to achieve this) and the preliminary findings from evaluating the environments with respect to student satisfaction and knowledge gain are limited and are obtained mainly with the use of graphs and descriptive statistics. These preliminary findings showed that students evaluated the environments positively. Their comments were also valuable in improving the environments.

As future work, the authors of this paper intend to investigate whether adding knowledge testing activities and games to videos have actually a positive effect in learning. In order to achieve this the authors plan to continue the research by carrying out a similar procedure (pre-test, video and in-video activities, post-test) using a similar student sample size and the same video (video presenting audio-visual production stages) but without the in-video activities. The data collected from the three experiments (video with 16 activities, video with ten activities and plain video) will be used in a more elaborate statistical analysis in order to research the effectiveness of progressive video interactivity in learning. This paper recorded only student perceptions on whether the environment had an impact on learning and the results were optimistic. A large percentage of students stated that the interactive activities helped them learn better and obtain better scores in the post-test. Furthermore, the authors intend to investigate learner behaviours and more specifically the way learners view and interact with the video and the in-video activities presented in this paper. As mentioned the environments contain an activity tracking module used for gathering user behaviour data. A large sample of viewing and activity data is collected using this module. This data sample will be analyzed using statistical and visualisation methods in order to obtain a better understanding of the way the environments were used by students.

\section{References}

Agarwala, M., Hsiao, I.H., Chae, H.S. and Natriello, G. (2012) 'Vialogues: video and dialogues based social learning environment', in 2012 IEEE 12th International Conference on Advanced Learning Technologies, July, pp.629-633, IEEE.

Bishop, J.L. and Verleger M.A. (2013) The Flipped Classroom: A Survey of the Research in American Society for Engineering Education Annual Conference, pp.5-7.

Chi, M.T. and Wylie, R. (2014) 'The ICAP framework: linking cognitive engagement to active learning outcomes', Educational Psychologist, Vol. 49, No. 4, pp.219-243.

Colasante, M. (2011) 'Using video annotation to reflect on and evaluate physical education preservice teaching practice', Australasian Journal of Educational Technology, Vol. 27, No. 1, pp.66-88.

Cummins, S., Beresford, A. and Rice, A. (2015) 'Investigating engagement with in-video quiz questions in a programming course', IEEE Transactions on Learning Technologies, Vol. 9, No. 1, pp.57-66.

Giannakos, M., Krogstie, J. and Chrisochoides, N. (2014a) 'Reviewing the flipped classroom research: reflections for computer science education', Proceedings of the ACM Computer, Science Education Research Conference, pp.23-29, ACM Press, New York. 
Giannakos, M.N., Jaccheri, L. and Krogstie, J. (2014b) 'Looking at MOOCs rapid growth through the lens of video-based learning research', International Journal of Emerging Technologies in Learning, Vol. 9, No. 1, pp.35-38.

Giannakos, M.N. (2013) 'Exploring the video-based learning research: a review of the literature', British Journal of Educational Technology, Vol. 44, No. 6, pp.E191-E195.

Girgensohn, A., Shipman, F. and Wilcox, L. (2003) 'Hyper-hitchcock: authoring interactive videos and generating interactive summaries', Proceedings of the Eleventh ACM International Conference on Multimedia, November, pp.92-93, ACM.

Kay, R.H. (2012) 'Exploring the use of video podcasts in education: a comprehensive review of the literature', Computers in Human Behavior, Vol. 28, No. 3, pp.820-831.

Kleftodimos, A. and Evangelidis, G. (2016a) 'An interactive video-based learning environment that supports learning analytics for teaching “image editing”, SE@VBL@LAK, pp.26-33.

Kleftodimos, A. and Evangelidis, G. (2016b) 'Using open source technologies and open internet resources for building an interactive video-based learning environment that supports learning analytics', Smart Learning Environments, Vol. 3, No. 1, p.9.

Kleftodimos, A. and Evangelidis, G. (2018) 'Augmenting educational videos with interactive exercises and knowledge testing games', 2018 IEEE Global Engineering Education Conference (EDUCON), pp.872-877, IEEE.

Kohen, D-V., Milrad, M., Ronen, M. and Jansen, M. (2016) 'Evaluation of enhanced educational experiences using interactive videos and web technologies: pedagogical and architectural considerations', Smart Learning Environments, Vol. 3, No. 1, p.6, https://oi.org/10.1186/ s40561-016-0029-z.

Kolås, L. (2015) 'Application of interactive videos in education', 2015 International Conference on Information Technology Based Higher Education and Training (ITHET), June, pp.1-6, IEEE.

Lin, C.Y., Tseng, B.L. and Smith, J.R. (2003) 'VideoAnnEx: IBM MPEG-7 annotation tool for multimedia indexing and concept learning', IEEE International Conference on Multimedia and Expo, July, pp.1-2.

Martin, F.G. (2012) 'Will massive open online courses change how we teach?', Communications of the ACM, Vol. 55, No. 8, pp.26-28.

Mayer, R.E. (2005) 'Principles for managing essential processing in multimedia learning: segmenting, pretraining, and modality principles', The Cambridge Hand-Book of Multimedia Learning, pp.169-182.

Merkt, M., Weigand, S., Heier, A. and Schwan, S. (2011) 'Learning with videos vs. learning with print: the role of interactive features’, Learning and Instruction, Vol. 21, No. 6, pp.687-704.

Motti, V.G., Fagá Jr., R., Catellan, R.G., Pimentel, M.D.G.C. and Teixeira, C.A. (2009) 'Collaborative synchronous video annotation via the watch-and-comment paradigm', Proceedings of the 7th European Conference on Interactive TV and Video, June, pp.67-76, ACM.

Preston, M., Campbell, G., Ginsburg, H., Sommer, P. and Moretti, F. (2005) 'Developing new tools for video analysis and communication to promote critical thinking', EdMedia + Innovate Learning, June, pp.4357-4364, Association for the Advancement of Computing in Education (AACE).

Reider, W.L. (1985) 'VCRs silently take over the classroom', TechTrends, Vol. 30, No. 8, pp.14-18.

Rich, P.J. and Hannafin, M. (2009) 'Video annotation tools: technologies to scaffold, structure, and transform teacher reflection', Journal of Teacher Education, Vol. 60, No. 1, pp.52-67.

Risko, E.F., Foulsham, T., Dawson, S. and Kingstone, A. (2013) 'The collaborative lecture annotation system (CLAS): a new tool for distributed learning', IEEE Transactions on Learning Technologies, Vol. 6, No. 1, pp.4-13, First Quarter.

Schaffer, L.C. and Hannafin, M.J. (1986) 'The effects of progressive interactivity on learning from interactive video', ECTJ, Vol. 34, No. 2, pp.89-96. 
Schwan, S. and Riempp, R. (2004) 'The cognitive benefits of interactive videos: learning to tie nautical knots', Learning and Instruction, Vol. 14, No. 3, pp.293-305.

Theodosiou, Z., Kounoudes, A., Tsapatsoulis, N. and Milis, M. (2009) 'Mulvat: A video annotation tool based on xml-dictionaries and shot clustering', International Conference on Artificial Neural Networks, September, pp.913-922, Springer, Berlin, Heidelberg.

Wachtler, J., Hubmann, M., Zöhrer, H. and Ebner, M. (2016) 'An analysis of the use and effect of questions in interactive learning-videos', Smart Learning Environments, Vol. 3,No. 1, p.13.

Yousef, A.M.F., Chatti, M.A., Danoyan, N., Thus, H. and Schroeder, U. (2015) 'Video-mapper: a video annotation tool to support collaborative learning in moocs', Proceedings of the Third European MOOCs Stakeholders Summit EMOOCs, pp.131-140.

Yousef, A.M.F., Chatti, M.A. and Schroeder, U. (2014a) 'Video-based learning: a critical analysis of the research published in 2003-2013 and future visions', The Sixth International Conference on Mobile, Hybrid, and On-line Learning, March.

Yousef, A.M.F., Chatti, M.A. and Schroeder, U. (2014b) 'The state of video-based learning: a review and future perspectives', International Journal On Advances in Life Sciences, December, Vol. 6, Nos. 3-4, pp.122-135.

Zhang, D., Zhou, L., Briggs, R. and Nunamaker, J. (2006) 'Instructional video in e-learning: assessing the impact of interactive video on learning effectiveness', Information \& Management, Vol. 43, No. 1, pp.15-27. 